\section{SIGNOS DO CONSUMO EM MÚLTIPLOS ENFOQUES}

O volume 13, número 1, de 2021 da revista Signos do Consumo traz um conjunto de artigos que abordam aspectos das discussões sobre o consumo material alimentar, gêneros (questões LGBT+ e das masculinidades), sobre a pesquisa em publicidade de modo mais amplo, sobre públicos e seus usos e consumos midiáticos (efetivos e possíveis) e sobre o consumo dos signos religiosos.

Esses múltiplos enfoques não revelam apenas uma diversidade temática, mas também dão voz aos trabalhos de uma gama de pesquisadores das regiões Nordeste, Sudeste e Sul do país, dedicados aos estudos da publicidade, comunicação e consumo, mostrando a abrangência que os fenômenos da contemporaneidade oferecem à reflexão dos signos do consumo como espaço de grande potência e de contribuição social aos estudos da Comunicação.

Esta edição começa com o artigo "Dimensões do consumo sustentável no comportamento de consumidores de alimentos saudáveis”, dos autores Diego de Queiroz Machado, Noelle Rigel de Oliveira Cidade, Claudia Buhamra Abreu Romero, Hugo Osvaldo Acosta Reinaldo e Winny Rebouças Mota, da Universidade Federal do Ceará, que trazem a discussão da cultura material alimentar na perspectiva do consumo sustentável e mais saudável.

Arize Souza Fernandes de Oliveira e Mônica Machado, da Universidade Federal do Rio de Janeiro, levantam, no artigo "Mais do que dinheiro: pink money e a circulação de sentidos na comunidade LGBT+", a temática recorrente da discussão de gêneros, orientada às questões LGBT+ e aos simbolismos do seu poder de consumo.

Também na esteira dos temas de gênero e consumo, Danilo Postinguel, da Escola Superior de Propaganda e Marketing de São Paulo, apresenta o texto fruto de suas investigações: "A pesquisa sobre as masculinidades no campo da comunicação: estado da arte de teses e dissertações na base Capes entre 1999 e 2018”, manifestando o primeiro registro dos artigos de pesquisas sobre publicidade e consumo que também dão o tom dos enfoques desta edição.

Na sequência, passa-se à discussão sobre públicos e consumos midiáticos de Letícia Alves Lins, da Universidade Federal de Minas Gerais, que aborda a questão do público em redes sociais digitais no artigo "A publicidade e os públicos nas redes digitais: uma proposta analítica para o mapeamento de embates discursivos", com uma importante contribuição metodológica aos estudos interacionistas dos consumos e usos midiáticos em redes sociais digitais.

Abordando a "Consubstancialidade: uma reflexão conceitual para pesquisas em publicidade”, Carolina Minuzzi e Juliana Petermann, da Universidade Federal de Santa Maria, configuram a segunda contribuição desta edição à compreensão das pesquisas realizadas no âmbito do eixo publicidade e consumo.

Em "Trecos móveis: a mobilidade em potência e o novo papel social dos objetos na publicidade das marcas”, Maria Alice de Faria Nogueira, da Universidade Estácio de Sá, apresenta sua abordagem sobre a perspectiva da mobilidade como eixo teórico de interpretação das realidades de consumo.

"A telerrealidade e o consumo de mundos", a partir da televisualidade, é tratada no artigo de Gabriel Souza e Fernanda Sagrilo, da Universidade

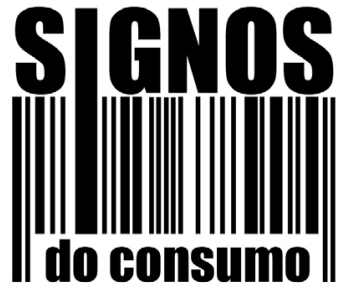

apresentação 
Federal de Santa Maria e da Universidade Federal do Pampa, apresentando o registro do consumo midiático televisivo possível em seu horizonte filosófico-teórico.

Encerrando os artigos desta edição, temos o prazer e a honra de publicar o texto de Lúcia Santaella, Carla Dendasck e Danielle Ferraro, da Pontifícia Universidade Católica de São Paulo, que nos brindam com a reflexão, "Leitura semiótica do Templo de Salomão e o consumo da fé”, manifestando a abordagem do consumo dos signos religiosos no contexto deste número.

E, por fim, tem-se a resenha "Gordofobia na moda plus size", de Maria Luisa Jimenez-Jimenez. A obra, originada de tese de doutorado de destaque no PPGCOM da Escola Superior de Propaganda e Marketing de São Paulo, em 2020, faz reflexões e críticas importantes sobre o mercado de moda plus size, além de discutir os caminhos do combate à gordofobia a partir da moda e de sua comunicação.

Cabe registrar ainda que a qualidade acadêmica dos artigos apresentados nesta revista é fruto do valioso trabalho de avaliação dos pareceristas, aos quais manifestamos nossos agradecimentos pelo trabalho de avaliação dos textos deste número: Alhen Damasceno, Anderson Lopes da Silva, Carolina Boari, Eliã Simeia, Elisa Piedras, Francisco Leite, Lívia Silva de Souza, Maria Lília Dias de Castro, Maria Ogécia Drigo, Milena Freire, Nicolás Llano Linares, Rosana Mauro, Selma Felerico, Silvio Sato, Taciana Burgos e Tania Hoff.

Os signos do consumo, em seus múltiplos enfoques, propiciam o contato com novos saberes e ensejam reflexões de relevância social e cultural que fortalecem o campo das pesquisas em comunicação e consumo.

Desejamos a todas e todos uma ótima leitura!

Clotilde Perez e Eneus Trindade Os editores. 